\title{
EXAMINING NONLINEAR RELATIONSHIPS BETWEEN QUALITY \\ MANAGEMENT AND FINANCIAL PERFORMANCE
}

\begin{abstract}
A thorough analysis of nonlinear relationships between Quality Management (QM) and organizational outcomes has largely been ignored in the current empirical QM literature, which can have profound theoretical and managerial implications. The existence of nonlinear relationships implies taking a contingent view in that QM practices are more effective depending on their level of implementation in an organization. The present research focuses on this possibility and undertakes an in-depth study of the sparse nonlinear relationship suggested by the literature. We introduce an empirical study carried out on a sample of 168 service firms belonging to sectors experienced in QM and, through polynomial regression analysis, identify the nature of the relationship between QM and financial performance (return on assets). The results, by showing an S-shaped curve, support a nonlinear association between these two variables. The presence of this functional form provides a satisfactory solution to the growing debate among researchers who, from a linear perspective, defend the positive effects of QM on organizational outcomes, those who find no significant effect, and still others who claim that QM has a negative effect. Our results show that in organizations with a low level of QM implementation, managers should increase investment in QM, even though this increase will not be correspondingly beneficial in the same proportion. In contrast, in organizations with a high level of QM implementation, managers are advised to reflect on undertaking projects that represent an additional investment in QM, with the aim of finding their optimal level.
\end{abstract}

Keywords: Quality Management, financial performance, curvilinear relationship, contingent view 


\section{INTRODUCTION}

One important area of research in Quality Management (QM) has been the examination of the extent to which QM practices have an impact on financial performance. Nevertheless, QM scholars have produced mixed and paradoxical findings. As Sousa and Voss (2002) suggest, the sign and the significance of the impact of QM on financial performance are not always straightforward. Both sides (positive versus negative) of QM effectiveness can draw upon numerous examples to support their relative position (Wayhan and Balderson, 2007). These contradictory findings about the QM-performance relationship may be due to these practices being context dependent (Sousa and Voss, 2008). These authors advise that in mature operation scenarios, management practices such as QM should shift their focus from justifying the value of these practices to understanding the contextual conditions under which they are effective. This idea falls in line with the contingent approach that some studies have developed in the field of QM, which has been adopted in previous empirical studies (e.g., Hendricks and Singhal, 2001; Jayaram et al., 2010; Sousa and Voss, 2008) exploring how the relationship between QM and firm performance can be moderated by organizational and contextual factors.

Working on this contingent view to QM, previous findings in the extant literature (e.g., Chapman and Al-Khawaldeh, 2002; Easton and Jarrell, 1998; Hendriks and Singhal, 2001; Lai et al., 2012) suggest that the level of QM implementation in the organization can be analyzed as a moderator variable. Although these authors continue to adopt a linear approach, taking into account the level of QM as a moderator of the relationship between QM and organizational performance leads us to consider the existence of nonlinear effects. Nonlinear relationships can be conceptualized as a special case of the more general moderated relationships, in which the relation between a predictor $X$ and a desirable outcome $Y$ is expected to change as values of the same predictor $X$ vary (Pierce and Aguinis, 2013). In this line, Chapman and Al-Khawaldeh (2002) and Lai et al. (2012) already briefly venture the prediction that, according to the results of their studies, the relationship between QM and firm performance may be nonlinear. An in-depth examination of the potential existence of a nonlinear relationship therefore still remains an open research question. In an attempt 
to respond to this question, the purpose of this paper is to explore the nonlinear relationships between QM and financial performance.

This paper contributes to the existing QM literature in several ways. First, to our knowledge, this is the first study that explicitly presents and brings together the whole range of nonlinear options suggested over time in the empirical QM literature and, by means of a polynomial regression analysis, a statistical technique commonly used to examine a curvilinear relationship (Aiken and West, 1991; Cohen et al., 2003), carries out an empirical study to examine whether there is a nonlinear relationship between QM and financial performance, and the pattern of this relationship.

Second, although an overall curvilinear pattern involves a greater degree of complexity than simpler linear models, the nonlinear effect provides an enhancement and makes a value-added contribution to theory and practice because it accounts for a wide range of inconsistent and apparently paradoxical findings (Aiken and West; 1991; Meilich. 2006; Pierce and Aguinis, 2013). Hence, conflicting results from previous linear contributions about the QM-performance relationship could be solved by proposing the existence of a curvilinear relationship (i.e., nonlinear) between these two variables. In this case, a point of inflection (maximum and minimum of the curve) is seen where the change of sign occurs, and therefore a negative relationship can coexist with a positive one.

Third, as well as the classic literature on the costs of quality (e.g., Crosby, 1979; Juran 1988) that identifies various nonlinear functional forms depending on the balance between the components of the costs of quality (i.e., prevention, appraisal, and failure-related costs), in this study we add to this debate another set of theoretical arguments that support a curvilinear pattern. Thus, for example, economic arguments such as scale effects and decreasing marginal returns justify the existence of nonlinear relationships between QM and financial performance.

To achieve our purpose, the paper is structured as follows. The following section presents the literature review, the theoretical arguments and the theoretical research hypotheses. The next section describes the main characteristics of the database used in the empirical analysis, the measures of variables and the methodology used to test the hypotheses. We then present the results obtained 
from estimating the empirical models. Finally, we discuss these results and summarize the main conclusions drawn from the study, as well as future research lines.

\section{THEORETICAL FRAMEWORK}

Organizational phenomena are notoriously complex with many obvious and less obvious effects on organizational outcomes (Meilich, 2006). Each phenomenon typically has both benefits and disadvantages on whatever outcome is examined. A linear relationship assumes this balance to be constant. However, as the level of the organizational variable changes, it is reasonable to assume that the balance of benefits and drawbacks will change, and such behavior is represented by a curvilinear relationship between organizational phenomena and outcomes (Meilich, 2006). In transferring these considerations to the field of QM, some empirical evidence and theoretical arguments seem to support the idea that meaningful, large nonlinearities could exist in the relationship between QM and financial performance. As Lederer and Rhee (1995) and Sousa and Voss (2002) point out, according to this interpretation, quality may not always be free.

In this vein, one line of research that identifies nonlinearities between QM and performance is the economic models of quality (e.g., Crosby, 1979; Fine, 1986; Freiesleben, 2004; Juran, 1988; Lederer and Rhee, 1995; Yasin et al., 1999), which argues that QM initiatives have costs and benefits and, depending on whether or not the costs exceed the benefits, different nonlinear relationships may arise between QM and organizational outcomes. The impact of QM investments on profits can have different shapes depending on the company's QM level at the time it makes the investment (Freiesleben, 2004). These economic models of quality fall within the deductive perspective of the QM literature (Foster and Adam, 1996), which has focused on quantifiable variables and refers to mathematical operation modeling. Nonlinear models are often found in deductive research, mainly based on the work of Juran (1988) and Crosby (1979).

Alternatively, the empirical approach in the QM literature is observation based and involves data gathered from organizations usually through surveys (Foster and Adam, 1996). In contrast to the deductive perspective, some empirical research following this approach alludes to nonlinear models, 
although it does not specifically address them. One empirical study that suggests the possibility of a nonlinear relationship is that of Flynn et al. (1995). These authors considered the strength of quality practices (level of implementation of QM practices) as a dependent variable and quality performance as an independent variable, concluding that firms that achieved high and low quality performance reported similar (strong) quality management practices; while those firms that achieved intermediate levels of quality performance used inferior quality management practices. They suggest that this nonlinear relationship is an intriguing finding, running counter to previous thinking, and claim that "the specific form of the relationship between quality management practices and quality performance needs more study" (Flynn et al., 1995; p. 19).

Taking up Flynn et al.'s suggestion, some studies and arguments subsequently seem to infer various nonlinear forms in the relationship between QM and performance. Unlike Flynn et al. (1995), all these studies considered the level of QM implementation as the independent variable and performance as the dependent variable. Adopting this more usual perspective in QM research, in Figure 1 we have summarized these nonlinear relationships, from simpler models (quadratic) to more complex models (cubic). Below we discuss the theoretical arguments that would support each kind of relationship.

Figure 1

\section{U-shaped relationship between QM and performance}

Some evidence in the literature hints at this kind of relationship. Hendricks and Singhal's (2001) conclusions suggest that firms with more mature QM implementation (with a high level of QM) will have a higher rate of positive change in financial performance than less mature firms. Similarly, Chapman and Al-Khawaldeh (2002) show that the relationship between QM and labor productivity is positive with an unusual curvilinear relationship, because this relationship exhibits a low positive slope for companies with a lower QM implementation level.

This upward inflection in a positive relationship between QM practices and financial performance could be explained by Crosby’s (1979) “Quality Management Maturity Grid”, based on 
five levels of maturity (Uncertainty, Awakening, Enlightenment, Wisdom and Certainty) for the incremental adoption of QM in an organization. This maturity model suggests that the positive effect between QM improvement activities varies among the different maturity levels in the grid, since quality costs fall from $20 \%$ as a percentage of sales at the Uncertainty level, to $2.5 \%$ at the Certainty level. This decrease between levels is not linear. For instance, between the Uncertainty and Awakening levels there is a difference of 2 points, while between the Wisdom and Certainty levels the difference is 5.5 points. The most positive effect of QM on performance would be at a high level of implementation of QM (last stages in the grid), while at a low level (first stages in the grid) this positive effect appears to be smaller. Although Crosby does not exactly define the nature of this positive progression (linear vs. nonlinear), his data point to a nonlinear progression. Note that a simple linear model of the relationship between QM and performance posits that a one-unit increment in the QM variable will be linked to a difference of the same magnitude in the value of the dependent variable (i.e., organizational performance). Therefore, to use the terminology of Aiken and West (1991), Crosby seems to defend the existence of a predominantly positive concave upward curve between QM and organizational performance.

Apart from the viewpoint of Crosby's Maturity Grid, this U-shaped relationship may also be explained by scale effects. That is, at a low level of QM, where scale effects are absent, the investments and efforts necessary for QM implementation and development could be greater than the gains obtained. Implementing QM is not without its costs. Firms may have made high investments in process management and new equipment to implement continuous improvement and quality methods. In addition, especially at low levels of QM, significant resources are expended to train employees and reorganize firms to deploy a quality philosophy and customer orientation throughout the organization (Lederer and Rhee, 1995). All this can derive in a weak positive, or even negative, effect of QM on performance. When the level of QM implementation increases, scale effects arise from complementarities among different QM practices and fixed costs are spread over more employees. For example, top management team involvement is recommended as an essential complement to extend the quality philosophy at all levels and among all people of an organization. 
Similarly, total quality methods (hard QM element) are coupled with quality-related training (soft QM element) to achieve better organizational effectiveness. On the other hand, scale effects result from spreading over more employees (or areas in an organization) the fixed administrative expenses associated with management by fact (i.e., investments in information technologies to manage quality data). The expenses of training activities also have a notable fixed cost component, therefore resulting in a lower unit cost, the higher the number of employees in the organization.

Moreover, authors such as Douglas and Judge (2001), Hendricks and Singhal (2001) and Yeung et al. (2006) advocate that organizations adopting QM without entrenching it (less advanced adoption) are unlikely to produce benefits. Indeed, Brah (2000) suggests that rigor of implementation is one of the factors that most influences QM success, more than other factors such as QM duration. As Douglas and Judge (2001) state, the rhetoric that surrounds it and the mere presence of a QM program are not sufficient for success; on the contrary, there is a need for an integrated and entrenched QM initiative. This ingrained view is only achieved at high levels of QM implementation (Ryan and Moss, 2005). In other words, according to Yeung et al. (2003), when non-advanced QM firms implement QM at a relatively partial and superficial level, the QM initiative is not comprehensive enough to induce a chain reaction that improves overall efficiency. In contrast, when QM is implemented with deeper effects on related systems, this chain reaction is expected and a stronger effect of QM on performance is probable. In light of the above contributions, the following assumption can be made:

Hypothesis 1: There is a concave upward curvilinear relationship between QM and organizational outcomes: the higher the degree of implementation of $Q M$, the more positive the effect of $Q M$ on organizational outcomes will be.

\section{Inverted U-shaped relationship}

One initial explanation for this relationship lies in the arguments presented by Juran (1988) from the traditional model of quality costs. There is an optimum quality level, above which it ceases to be advantageous for firms to invest in improving quality since total quality costs instead of falling, would increase. Following Juran's arguments, Freiesleben (2004) claims that both the costs and the 
revenue impact of quality improvements need to be assessed in order to determine how much improvement is optimal at a current quality level. Taking into account that a firm is likely to go through several stages of improvements, this author concludes that if a company has a low level of QM implementation, investment in quality improvement lowers its production costs and increases its revenues and, in most cases, these benefits are greater than the costs of the improvement. This would be explained by the fact that when firms have a low level of QM implementation they target some specific initiatives to pick the "low hanging fruits" first (Mohammad et al., 2011). According to this idea, it may be easier to implement improvements in non-advanced QM organizations because the potential for improvement is greater, and also because the most important quality issues (with the most potential), which have a direct impact on performance, and those that are easiest to solve are dealt with first. This may mean that, even at the cost of greater effort and investment, at a high level of QM implementation outcomes do not improve as strongly as when a firm has a lower level of performance, and may even be counterproductive, thus giving rise to a negative effect.

Another explanation is derived from a standard assumption in modeling organizational performance, namely, that the marginal utility of investments in organizational assets declines after a certain point (Chadwick, 2007). Beyond this point of decreasing marginal returns, the slope of a positive relationship falls and may eventually become negative as the incremental returns generated by further investments become increasingly less capable of recovering their costs. In a QM context, Patterson et al. (2004) suggest that management practices such as QM have reached a high point of institutionalization and are used to an optimum point, after which returns on further investments may diminish. Additionally, Fullerton et al. (2003) present evidence that returns from quality investments are positive, but decline as the degree of QM implementation increases. Their study suggests that higher level implementation of QM practices reduces the profitability of the sample firms as trade-offs between cost and quality can affect financial performance negatively.

Finally, from the point of view of the impact QM has on employees, high QM implementation would also be a way of tightening managerial control over the workforce, thereby intensifying work, which might have negative repercussions on workers' performance that, in turn, 
could negatively affect organizational performance (Godfrey et al., 1997). For instance, Ghobadian and Gallear (2001) show how activities like employee participation, quality meetings, periodic reviews, formal self-assessment or suggestion schemes-all of which could step up work intensification and employee pressure-are common among more advanced QM implementers. In contrast, where there is a lower level of implementation, these authors suggest that the firm should focus on taking steps to help to improve the clarity of organizational objectives, or establish training activities or assessment of "employee perception", which can improve employees' perception of this kind of management practice, and consequently make them more motivated and satisfied in their jobs.

Therefore, at higher levels of QM practice implementation, there will be a point beyond which greater implementation will yield decreasing returns because it is difficult to develop actions leading to significant improvements due to the low potential for improvement, the decreasing marginal utility effect appears, and effects emerge that are detrimental to employee performance. The above leads us to our next assumption:

Hypothesis 2: There is a concave downward curvilinear relationship between QM and organizational outcomes: the bigher the degree of implementation of QM, the less positive the effect of QM on organizational outcomes will be.

\section{Cubic relationships between QM and performance}

In some relationships the relative strength of opposing effects may vary several times over the full range of an explanatory variable, which would suggest higher order functional forms, such as a cubic form. Chadwick (2007) points out that U-shaped and inverted U-shaped relationships can be complementary, giving rise to a cubic relationship. In the QM context, if both hypotheses occur, the relationship between QM and organizational outcomes will have two inflection points, it would be a cubic relationship and could resemble the curves depicted in Figure 1b. Thus, the two-in principle opposing-nonlinear visions outlined above become compatible. Crosby (1979), for example, does not accept the optimal quality level (i.e., inverted U-shaped relationship) argument defended by Juran 
(1988), as he argues that higher quality always reduces costs and raises profit, following his idea that "quality is free". If we propose a cubic relationship, then both quadratic relationships occur simultaneously, although at different levels of QM implantation. The explicit identification of a cubic curvilinear pattern is not commonly found in the QM research. However, some authors suggest this kind of relationship (e.g., Lai et al., 2012; Yasin et al., 1999). A common trait of these studies is that they locate one of these two quadratic relationships at different levels of QM implementation, adding another series of nonlinear arguments to justify them or based on previously raised arguments. The new scenario depicted by these authors leads to the predominance of a certain quadratic curvilinear relationship at a certain level of QM implementation.

In this vein, on the one hand Yasin et al. (1999) suggested an S-shaped relationship between QM and organizational outcomes. From the perspective of the economic cost of quality, these authors depict a relationship between investments in quality and overall organizational effectiveness that shows a concave downward shape (as Juran suggests) at high levels of implementation, and a predominantly positive concave upward shape at low levels (as Crosby suggests). In their curvilinear relationship, at a low level of QM implementation there is a moderate positive effect of QM in performance, which may be due to the lack of scale effects. At an intermediate level of QM implementation an inflection point appears where a strong positive relationship between QM and organizational outcomes arises, which shifts from gradual growth to a decrease as it moves toward higher levels of QM. The optimal point is reached where the slope of this relationship is zero and a maximum return on quality investment is obtained at a high QM implementation level. The arguments of Yasin et al. (1999) are that the optimal point of QM mainly occurs because at high levels of QM, when a notable level of customer satisfaction has been achieved, additional investments aimed at improving quality will not lead to additional benefits for the firm unless the projects are well-focused and based on a thorough understanding of the operating environment. These extra investments entail additional expenses and increase the price of services but provide little or nothing in terms of value added for the client, which leads to a decrease in overall effectiveness. In consequence, these authors hold that an inverted U-shaped curve appears when there is a high 
level of implementation. In the same line, Ho et al. (2006) argue that when a firm is in a stage of high customer satisfaction, it tends to overinvest, because it is optimal to invest in customer satisfaction up to a level below 100\%. Customer satisfaction can be increased by investing in costly technology or productive processes and if this happens the implications of these investments for revenues from the value added for the client must be evaluated. These costs can exceed the revenues, and profit will decrease as customer satisfaction become higher. Drawing on Yasin et al.'s (1999) arguments, we formulate the following hypothesis:

Hypothesis 3: There is a concave upward curvilinear relationship between QM and organizational outcomes at a low degree of implementation of QM and a concave downward curvilinear relationship between $Q M$ and organizational outcomes at a high degree of implementation of QM (S-shaped curve).

On the other hand, some authors have suggested an inverted S-shape. From the economic models of quality, Fine (1986) extended the Juran model by including the effects of organizational learning resulting from quality improvement processes and argues that firms may learn faster at a high quality level than at a low quality level. According to this author, this approach resolves the "quality is costly" (Juran’s idea) versus "quality is free" (Crosby’s idea) conflict. Fine's economic model holds that at the intermediate stage of QM implementation (on the way to quality), at a given level within this medium range a negative effect can appear. However, as higher levels of implementation are reached the greater efficiency resulting from the learning effect will cause the positive effect to prevail. Beyond the arguments from the economic models of quality, Lai et al.'s (2012) findings also suggest that the strength of the positive relationship between QM implementation and firm performance varies between different QM implementation levels. Specifically, this relationship is weaker for firms with a medium level of QM implementation, but stronger for organizations that have a low level of QM implementation and those that achieve a consistently high level of QM implementation. Consequently, these authors hold that a U-shaped curve will be observed at a high level of implementation. The more intense effect of QM on results at lower levels of QM implementation may be explained by the "low hanging fruits" effect. On the other hand, the entrenching or comprehensive implementation of QM argument will drive the more 
intense effect of QM at high levels than at medium levels. As Lai et al. (2012) explain, the complementary nature or interface of the different elements of QM (production and marketing) to achieve superior performance appears especially at high levels of implementation. The problems of integrating the two elements are present at an intermediate level of implementation and reduce the intensity of the positive relationship, even when the level of performance rises. In sum, Lai et al. (2012) find a nonlinear relationship between QM and firm performance similar to that in Figure 1 (hypothesis 4) and we can therefore propose the following hypothesis:

Hypothesis 4: There is a concave downward curvilinear relationship between QM and organizational outcomes at a low degree of implementation of $Q M$ and a concave upward curvilinear relationship between QM and organizational outcomes at a high degree of implementation of QM (inverted S-shaped curve).

\section{METHODOLOGY}

\section{Sample}

Our research was addressed to service organizations in Spain with 50 employees or more. Sampaio et al. (2012) find that QM is widespread in Spain, and it represents an appropriate context to study this kind of initiative. Moreover, according to Jayaram et al. (2010), by centering our study on relatively larger organizations we ensure a certain expertise in QM. We selected medium-sized and large firms in line with European Union criteria (Recommendation of European Commission $2003 / 361 / E C)$, that is, firms with 50 workers or more. Our research was completed for various service sectors positioned on the volume/variety continuum (Silvestro, 2001), chosen according to their SIC code (SIC-70 hotels; SIC-73 business services; and SIC-87, which includes professional services such as auditors or technical engineers). The study of these sectors provides an appropriate field to study QM as they are sectors where quality has been an important variable to compete, and where many QM initiatives are being adopted (Claver et al., 2008; Holschbach, 2013). Sousa and Voss (2008) state that it is precisely in these sectors with mature QM implementation where, rather than examining the value of QM practices, it is more interesting to explore the contextual conditions under which they are effective. 
Considering the whole population of firms in these three sectors, we extracted a list of 1,373 medium-sized and large firms from the Spanish national ARDAN database. Organizations were randomly selected from this list, and a professional market research company was hired to collect data about QM implementation. The fieldwork was carried out during January and February 2006 by means of personal face-to-face interviews and using a structured questionnaire; the quality manager was the key informant in each firm. From the 180 valid responses obtained, we eliminated 12 from our analyses because they did not provide the full data. Hence, 168 organizations were used in our empirical research. Of these firms 96 had a quality system certificate and 72 had no certification. Given that the population comprised 1,373 firms, a sample of 168 implies a sampling error of \pm 7.08 $\%$ for the overall sample, considering a confidence level of $95 \%$ and in the worst-case scenario $(\mathrm{p}=\mathrm{q}=50 \%)$.

\section{Measures}

\section{Degree of implementation of QM}

Following Douglas and Judge (2001), we operationalize the degree of QM practices adopted as a multidimensional construct made up of seven dimensions that capture the domain of QM. These authors grouped QM elements into the following seven dimensions: focus on the customer, continuous improvement of processes, top management team involvement, adoption of a quality philosophy, emphasis on QM-oriented training, management by fact, and use of QM methods. We used the items proposed by Douglas and Judge (2001) to measure each QM dimension, since these items gather common elements of QM, and were designed for research in the service sector. In a recent study, Escrig-Tena et al. (2012) also validated this measurement instrument in service sectors. Bearing in mind the procedure used by Douglas and Judge (2001) or Albacete et al. (2011), we computed the aggregated average of the seven dimensions to create a QM variable that was used in the subsequent regression analysis.

\section{Financial performance}

A major challenge to research examining the association between QM and firm performance has been the availability of objective financial data (Hendricks and Singhal, 2001). Authors such as 
Wayhan and Balderson (2007) recommend using this type of indicator as a way of solving problems such as common variance. We therefore used objective financial data from the ARDAN database. As in previous studies (e.g., Corredor and Goñi, 2011; Martínez-Costa et al., 2008), we chose the return on asset (ROA) as the indicator of financial performance because it covers the two main routes for the effect of QM on financial performance-the production (internal) route, and the market (external) route (e.g., Sousa and Voss, 2002).

Moreover, the cross-sectional nature of the majority of studies that have analyzed the relationship between QM and financial performance could be considered as a limitation to establishing causal inferences (Corredor and Goñi, 2011; Easton and Jarrell, 1998; Martínez-Costa, et al., 2008). To avoid this limitation and help control for reverse causality, a longitudinal research design is suggested. In our study we use objective financial ratios referring to two years before (2004 and 2005) and two years after (2006-2007) the measurement of QM practices. The impact of QM on financial performance is likely to be spread over several years. Despite the lack of consensus, the QM literature does provide some guidance on what the appropriate length of time should be for examining performance. Based on the recent empirical study by Boulter et al. (2013), we consider it acceptable to focus on change in financial performance over two years after measuring the extent of QM implementation. In the Spanish context, Martínez-Costa et al. (2008) chose a similar period of time. Moreover, it is not advisable to include 2008 and subsequent years in the study because the financial crisis that took hold in Spain at this time would have significantly distorted financial results. Finally, similarly to Corredor and Goñi (2011), we calculated the mean of the financial indicator for the years 2004 and $2005\left(\mathrm{ROA}_{0405}\right)$ and introduced it as control variable of the financial indicators for the two following years, 2006 and 2007, $\left(\mathrm{ROA}_{0607}\right)$, which was introduced as dependent variable in the regression analysis. The mean of the two years ensures the measure has some stability.

\section{Control variables}

In addition to the financial performance prior to measuring QM, we introduced a further three control variables, namely, firm size (measured as the logarithm of number of employees), QM duration (measured via a specific question asking for the number of years the organization has 
experience with QM) and business sector. These variables have been analyzed in previous studies as firm characteristics that can influence results in the context of QM (e.g., Hendricks and Singhal, 2001; Jayaram et al., 2010).

\section{Statistical procedure}

Following the recommendations of Aiken and West (1991) and Cohen et al. (2003), the hypotheses were tested using hierarchical regression analysis. The independent variable (QM) is centered to prevent multicollinearity problems between linear, quadratic and cubic terms. Model 1 was limited to examining the direct and individual effect of the control variables. In Model 2 we added the QM variable and present the traditional linear model with no bends. Model 3 shows the quadratic model with one bend. Model 4 presents the cubic equation with two bends (see Table 2). To select the model that best fits the data, we employed statistical significance attributable to the higher term in the polynomial equation and sequentially compared the values of the explained variance $\left(R^{2}\right)$ of the different models. The tests for statistical significance in the increase of $R^{2}$ observed are an appropriate way to evaluate the impact of the variables introduced. A further criterion consists of examining the change in adjusted $R^{2}$. Unlike the increment in the $R^{2}$ observed, this change may be positive or negative and a reasonable criterion for deciding between two equations is a value between 0.02 and 0.05 (Cohen et al., 2003).

\section{RESULTS}

Correlations and descriptive statistics of the variables used in our analysis are shown in Table 1. Tables 2 reports the results of the regression analyses and shows the effect of QM on ROA. In Table 2, when the QM term is introduced into Model 2 no significant increase is observed in the explained variance between Models 1 and $2\left(\Delta R^{2}: 0.006\right)$; in other words, the regression coefficient of QM (0.075) is not significant and, therefore, there is no empirical evidence of a linear interrelationship between QM and ROA. Likewise, when the quadratic term $\mathrm{QM}^{2}$ is added into the regression equation in Model 3, $R^{2}$ does not increase and neither is this quadratic term $(-0.015)$ statistically significant. The data therefore do not support the relevance of the quadratic aspect of 
QM to ROA. The addition of the cubic term $\mathrm{QM}^{3}$, in contrast, does make a substantial difference, with a significant increment of $R^{2}$ observed $\left(\Delta R^{2}: 0.032\right)$, and it also shows a statistical significance attributable to this higher term (-0.504) in the polynomial equation. If we examine the change in adjusted $R^{2}$ we find a moderate effect size when we compare the cubic equation with the quadratic $(0.029=0.268-0.239)$ and lineal $(0.024=0.268-0.244)$ models. Considering these criteria as a whole, we conclude that this regression equation is curvilinear and, more particularly, that is cubic. The fit of the cubic equation to the data visibly improves, although the match is not perfect. The best fitting equation utilizing $Q M, Q M^{2}$ and $Q M^{3}$ (i.e., Model 4) will account for more $R O A$ variance in the population than one that has only $Q M$ and $Q M^{2}$ (i.e., Model 3) or only $Q M$ (i.e., Model 2). In the cubic equation, the negative sign of $\mathrm{QM}^{3}$ indicates a curve that is first concave upward and then concave downward as the QM level increases, thus confirming our research hypothesis 3, which proposed an S-shaped relationship between QM and financial performance.

Table 1

Table 2

A graphic representation of a nonlinear model enables a better understanding of the results, as it allows us to identify the exact shape of this relationship and observe which values of QM are associated with values of financial performance. Thus, in Figure 2 we present the cubic S-shaped relationship between QM and ROA (Model 4 of Table 2). Pierce and Aguinis (2013) suggest including the full range of scores on the predictor variable to detect nonlinearity. Following this recommendation, in order to illustrate the curvilinear relationship between QM and financial performance and identify inflection points, we show this relationship for the entire range of values of the centered QM variable (minimum: -2.910; maximum: 1.500) for the sample of firms. However, authors such as Aiken and West (1991) and Cohen et al. (2003) advise interpreting and explaining the figure only within the representative values of the independent variable, which is a deviation above 
and below the mean value of that variable for the sample of firms analyzed. The polynomial regression equation plotted in a figure is uninformative at the extreme values of the predictor (QM in our study) because data at these extreme values are sparse. In this situation there is insufficient information to make a reliable judgment (Cohen et al., 2003). Table 1 shows that the standard deviation for the QM variable has a value of 0.806 ; we therefore limit the substantive interpretation of the results to the values between -0.806 and 0.806 in these figures. In Figure 2, this area is shown between dashed lines.

Figure 2

As can be seen in Figure 2, the maximum of the cubic equation lies at a QM value of 0.430 and the minimum at -1.610 . At these inflection points the relationship between QM and financial performance is zero and, therefore, QM has no significant effect on ROA. While the minimum of this curvilinear cubic relationship falls outside the representative range of QM values, the maximum is located within that range. Therefore, within the representative range this cubic relationship is a predominantly concave downward curve between QM and ROA. Specifically, Yasin et al. (1999) find the same interrelation pattern between investments in quality and organizational effectiveness. At low levels of QM implementation a positive effect on financial performance appears, which reduces in intensity until it disappears, where the inflection point at which the maximum value of financial performance is achieved. From this optimal QM value (0.430), an additional effort or increase in investment in QM is counterproductive since a negative relationship between QM and financial performance appears, and the level of financial performance gradually decreases. This means that at intermediate (0) and high (0.806) QM values, similar levels of ROA are achieved. Despite this, it can be seen how the level of ROA reached is lower at low levels of QM (-0.806) compared with intermediate and high levels of QM. Accordingly, there is evidence that, for the firms in this sample, it is more profitable to have a high level than a low level of QM. 


\section{CONCLUSIONS}

Meilich (2006) and Pierce and Aguinis (2013) suggest that a shift from linear to curvilinear models is needed to improve management theory and practice, regardless of the level of analysis and subfield of study. When a literature advances and progresses over time, more sophisticated and complex explanations tend to appear that postulate nonlinear rather than linear proposals (Aiken and West, 1991; Pierce and Aguinis, 2013). According to these authors, in many theories in organizational and social sciences the greater complexity of analyzing these nonlinear proposals means that they are also often left aside, even when there are theoretical arguments and empirical indicators to suggest that they have potentially existed for some time.

In light of this call to introduce the analysis of nonlinear effects into management literature, this paper has examined how the relationship between QM and financial performance is expected to change as the level of QM varies. An implication of the nonlinear effect is that theory development efforts should predict not only whether QM will be related to financial performance but also the points on the QM continuum where the QM-performance relationship will turn asymptotic and, if applicable, negative. To this end, we have used various theoretical arguments and past empirical research to posit competing hypotheses regarding the approximate location of these inflection points.

Our findings suggest that a convergence of nonlinear forces or effects occurs in an organization, which produces an S-shaped cubic relationship between QM and financial performance. This result is consistent with findings in previous studies such as Chapman and AlKhawaldeh (2002), Lederer and Rhee (1995) and Yeung et al. (2003) showing that, at low levels of implementation of QM practices, scale effects and the existence of a non-comprehensive QM initiative leads to a moderate positive effect of QM on performance. When the level of QM increases up to an intermediate level, scale effects arise and QM is more entrenched in the organization, which leads to investments in QM that derive in more intensive financial performance gains. When an organization reaches a high level of QM implementation, the reduced potential for improvement, the marginal utility of investments (Fullerton et al., 2003; Patterson et al., 2004), and work intensification 
(Godfrey et al., 1997) explain a weak positive or even negative effect of QM on performance. Hence this study provides support for the findings of Yassin et al. (1999) since an optimal point of QM occurs because at high levels of QM additional investments aimed at improving quality will not lead to additional benefits for the firm. Understanding this curvilinear relation is critical for both research and practice.

\section{Research implications}

First, our study supports the contention that substantial departures from linearity can occur in the relationships between QM and financial performance. Therefore, the linear relationship between these two variables should be considered as a relevant hypothesis that needs to be confirmed empirically, instead of taken as an initial premise, which has traditionally been the case in the QM literature. More specifically, as we have noted in our study, it is advisable to introduce nonlinear terms in empirical studies as a factor to explain organizational outcomes. If these terms had been omitted, nonlinearity would not have been detected even when it does exist (Aiken and West, 1991). Hence, for academics the analysis of nonlinearities, as suggested in papers such as Flynn et al. (1995), Hendricks and Singhal (2001), Lai et al. (2012) or Patterson et al. (2004), opens a field of research to design more precise specifications of the relationship between QM and firm performance.

In this regard it is interesting to highlight Edwards' (2009) reflection that hypotheses of the form "if $\mathrm{X}$ increases, $\mathrm{Y}$ will increase" do not stipulate that the relationship between the two variables is linear, but instead make the more modest claim that higher values of $\mathrm{X}$ are associated with higher values of $\mathrm{Y}$. As this author noted, in some instances, a monotonic relationship such as this might be conceived as curvilinear rather than linear. It is precisely this situation that is clearly seen in our study. Hence, for example, when we examine the relationship between QM and ROA within the low and intermediate range of values of QM (see Figure 2), we find that if QM increases, ROA increases (higher values of QM are associated with higher values of ROA), but this relationship is nonlinear because these increases are not in the same proportion for all the QM values from -0.806 to 0 . 
Second, this paper presents a new way to inform about how the relationship between QM and organizational outcomes works. The failure to obtain consistent results in the relationship between QM practices and financial performance could be due to significant differences among studies in terms of the different theoretical frameworks they use, or due to differences in research design issues (Nair, 2006). In addition to these, another possible interpretation of the conflicting results in the literature is that the relationship between QM and financial performance may be nonlinear. From a nonlinear view of QM research, QM can positively and negatively impact financial performance, depending on the degree of implementation of QM practices. For example, in our study this is clearly seen at the intermediate-high level of QM implementation, since an inflection point (maximum) appears at which the positive relationship between QM and ROA becomes negative (see Figure 2). We can thus reconcile the mixed previous findings regarding the impact of QM on financial performance by introducing nonlinearities in this relationship.

Third, another implication of the nonlinear effect for theory development concerns the reconsideration and expansion of the role of moderating effects in QM research. The identification of potential contextual variables that act as moderating factors in the relation between QM practices and performance presents a promising avenue of research (Nair, 2006). Our study contributes to the contingency theory of QM effectiveness, showing the level of QM as another moderating variable to be considered. In particular, our study responds to a query from some QM scholars, such as Chapman and Al-Khawaldeh (2002), Douglas and Judge (2001), and Hendricks and Singhal (2001), who point to the importance of assessing the degree to which QM practices are implemented when evaluating the relationship between QM and organizational outcomes. Our paper suggests this level of implementation as one of the contextual variables that conditions QM success. Thus, our research supports the contingent research in QM and advises scholars of the need to interpret results in light of the level of QM reached in an organization.

\section{Practical implications}

As Freiesleben (2004), Hendricks and Singhal (2001) and Yasin et al. (1999) point out, by providing evidence on how QM affects the financial performance of firms with different degrees of 
QM implementation, we offer an empirical basis for forming realistic expectations about the benefits of QM, which could be used to justify QM investments. The confirmation of an S-shaped curve between QM and financial performance should inform managers that investments in QM are not always correspondingly beneficial. In particular, it is important to highlight that within the representative range of values in our sample of firms, our study provides evidence that a negative relationship does not appear at a low level of QM. This relationship pattern encourages managers to invest in QM practices, resources and time in order to raise the level of QM so that these investments derive in increased results. This suggests that implementing an effective QM program may not result in poor performance when the level of QM implementation is low. This is important because managers often worry about the cost of implementing a QM plan.

In contrast, at a high level of QM implementation, increased investments in QM do not guarantee greater financial performance (ROA). Consequently, in these contexts, managers should find the optimal degree of implementation of QM practices. Fullerton et al. (2003) and Patterson et al. (2004) warn that excessive investment in and implementation of QM practices in firms may be counterproductive. Financial performance could deteriorate if the investment in QM is too large because some additional efforts may lead to a situation in which QM adds no value. Thus, beyond a certain high level of QM implantation, QM practices have a negative impact on financial performance. Nevertheless, despite this decline in firm profitability, our findings show that the level of financial performance reached is greater at higher levels than at lower levels of QM implementation. To sum up, a curvilinear relationship like the one revealed in our empirical study advocates that managers invest heavily in quality when their firms have a low level of QM and, in contrast, when the firm has a high level of implementation they should evaluate more carefully the benefits and costs of increasing investment in QM. We find that at intermediate and high levels of QM implementation similar levels of ROA are reached, which is because we identify an optimum point between these levels. 


\section{Limitations and future research}

We only focus on quadratic and cubic models; perhaps models with higher order polynomials should also be examined. As Cohen et al. (2003) point out, the nonlinear curve identified should make substantive sense; that is, the theory should guide the choice, and most theories in the social sciences predict quadratic, and at most cubic, relationships. As we have shown, the QM literature is no exception to this rule. Additionally, there may be problems with the quality of the data. For instance the problem of multicollinearity is very likely to occur in coefficients of higher order polynomials (above cubic). Because of all these drawbacks, Cohen et al. (2003) advise focusing on analyzing quadratic and cubic models to uncover and explain nonlinear interrelation patterns between two variables.

In the deductive approach (e.g., Fine, 1986; Foster and Adam 1996) it is usual for the time and level of implementation of QM in an organization to be used without distinction and in combination to explain the evolution and/or proportion of the different types of quality costs. Its premise is therefore that time is required to reach a high level of implementation. Hence, the two variables are confused and merge with each other. In contrast to these deductive studies, the empirical perspective usually distinguishes and delimits the two variables (e.g., Hendricks and Singhal, 2011). The two variables (QM level and QM duration) are separate concepts. By adopting this perspective in our study, the nonlinearity exclusively gathers the level of QM implementation in an organization. However, we recognize that the duration of QM implementation in organization is also a variable that affects economic performance (Hendricks and Singhal, 2011; Jayaram et al. 2010), and we therefore introduced it as a control variable in our empirical study (QM duration). Despite this, we believe it would be useful for future research to examine the time variable by adopting a dynamic perspective, namely, gathering measures of QM implementation at different moments in time.

Finally, we point out the need for future studies to include industrial firms and sectors where the implementation of QM initiatives is not so established in order to examine the existence of nonlinear relationships. Moreover, an international study would reveal whether or not our 
conclusions hold in other national contexts. Unquestionably, future studies that examine the potential existence of a nonlinear relationship between QM and organizational performance will help us assess more accurately whether, or under what circumstances, implementing QM is truly beneficial for firms. Our study is a preliminary attempt in this direction and clearly more future efforts are needed in this research line.

\section{REFERENCES}

Aiken, L.S., \& West, S.G. (1991). Multiple Regression: Testing and Interpreting Interactions. Newbury Park: Sage Publications.

Albacete, C., Fuentes, M.M., \& Bojica, A.M. (2011). Quality management, strategic priorities and performance: the role of quality leadership, Industrial Management \& Data Systems, 111(8), 1173-1193.

Boulter, L., Bendell, T., \& Dahlgaard, J. (2013). Total quality beyond North America: A comparative analysis of the performance of European Excellence Award winners. International Journal of Operations \& Production Management, 33(2), 197-215.

Brah, S.A., Wong, J.L., \& Rao, B.M. (2000). TQM and business performance in the service sector: a Singapore study. International Journal of Operations \& Production Management, 20(11), 1293-1312.

Chadwick, C. (2007). Examining Non-Linear Relationships between Human Resource Practices and Manufacturing Performance. Industrial \& Labor Relations Review, 60(4), 499-521.

Chapman, R., \& Al-Khawaldeh, K. (2002). TQM and labour productivity in Jordanian industrial companies. The TQM Magazine, 14(4), 248-262.

Claver, E., Pereira, J, Tarí, J.J., \& Molina, J.F. (2008). TQM, managerial factors and performance in the Spanish hotel industry. Industrial Management \& Data Systems, 108(2), 228-244.

Cohen, J., Cohen, P., West, S.G., \& Aiken, L.S. (2003). Applied Multiple Regression/Correlation Analysis for the Behavioral Sciences. Lawrence Erlbaum Associates: New Jersey.

Corredor, P., \& Goñi, S. (2011). TQM and performance: Is the relationship so obvious? Journal of Business Research, 64, 830-838.

Crosby, P. (1979). Quality is free: The art of making quality certain. New York: McGraw-Hill. 
Douglas, T.J., \& Judge, W.Q. (2001). Total Quality Management implementation and competitive advantage: the role of structural control and exploration. Strategic Management Journal, 44(1), 158-169.

Easton, G., \& Jarrell, S. (1998). The effects of Total Quality Management on corporate performance: An empirical investigation, The Journal of Business, 71(2), 253-307.

Edwards, J. R. (2009). Seven deadly myths of testing moderation in organizational research. In Lance, C. E. and Vandenberg, R.J. Statistical and methodological myths and urban legends: Doctrine, verity and fable in the organizational and social sciences. New York: Routledge, 143-164.

Escrig, A.B., Bou, J.C., Roca, V., \& Beltrán, I. (2012). Does quality management drive labour flexibility? Total Quality Management \& Business Excellence, 23(2), 159-176.

Fine, C.H. (1986). Quality improvement and learning in productive systems. Management Science, 32(10), 13011315.

Flynn, B.B., Schroeder, R.G., \& Sakakibara, S. (1995). Determinants of quality performance in high-and lowquality plants. Quality Management Journal, 2(2), 8-25.

Foster, S.T., \& Adam, E.E. (1996). Examining the impact of speed of quality improvement on quality-related costs. Decision Sciences, 27(4), 623-646.

Freiesleben, J. (2004). On the limited value of cost of quality models. Total Quality Management \& Business Excellence, 15(7), 959-969.

Fullerton, R.R., McWatters, C.S., \& Fawson, C. (2003). An examination of the relationships between JIT and financial performance, Journal of Operations Management, 21(4), 383-404.

Ghobadian, A., \& Gallear, D. (2001). TQM implementation: an empirical examination and proposed generic model. Omega, 29(4), 343-359.

Godfrey, G., Dale, B., Marchington, M., \& Wilkinson, A. (1997). Control: a contested concept in TQM research. International Journal of Operations \& Production Management, 17(6), 558-573.

Hendricks, K.B., \& Singhal, V.R. (2001). Firm characteristics, total quality management, and financial performance. Journal of Operations Management, 19, 269-285.

Ho, T. H., Park, Y.H., \& Zhou, Y.P. (2006). Incorporating satisfaction into customer value analysis: Optimal investment in lifetime value. Marketing Science, 25(3), 260-277.

Holschbach, E. (2013). Comparison of quality management for externally sourced business services. International Journal of Quality \& Reliability Management, 30(5), 530-570. 
Jayaram J., Ahire, S., \& Zhang, P.D. (2010). Contingency relationships of firm size, TQM duration, unionization, and industry context on TQM implementation-A focus on total effects, Journal of Operations Management, 28, 345-356.

Juran, J.M. (1988). Quality Control Handbook. New York: McGraw-Hill.

Lai, K.H., Yeung, A.C., \& Cheng, T.C.E. (2012). Configuring quality management and marketing implementation and the performance implications for industrial marketers. Industrial Marketing Management, 41(8), 1284-1297.

Lederer, P., \& Rhee, S. (1995). Economics of total quality management. Journal of Operations Management, 12(3), 353-367.

Martínez-Costa, M., Martínez-Lorente, A., \& Choi, T. (2008). Simultaneous consideration of TQM and ISO 9000 on performance and motivation: an empirical study of Spanish companies. International Journal of Production Economics, 113(1), 23-39.

Meilich, O. (2006). Bivariate models of fit in contingency theory. Critique and a polynomial regression alternative. Organizational research methods, 9(2), 161-193.

Mohammad, M., Mann, R., Grigg, N., \& Wagner, J. P. (2011). Business Excellence Model: An overarching framework for managing and aligning multiple organisational improvement initiatives. Total Quality Management \& Business Excellence, 22(11), 1213-1236.

Mohrman, S., Tenkasi, R., Lawler, E., \& Ledford, G. (1995). Total quality management: practice and outcomes in the largest US firms. Employee Relations, 17(3), 26-41.

Nair, A. (2006). Meta-analysis of the relationship between quality management practices and firm performance-implications for quality management theory development. Journal of Operations Management, 24, 948-975.

Patterson, M. G., West, M. A., \& Wall, T. D. (2004). Integrated manufacturing, empowerment, and company performance. Journal of Organizational Behavior, 25(5), 641-665.

Pierce, J.C, \& Aguinis, H. (2013). The too-much-of-a-good-thing effect in management. Journal of Management, 39(2), 313-338.

Ryan, C., \& Moss, S. E. (2005). Total quality management implementation: the "Core" strategy. Academy of Strategic Management Journal, 4, 61-76. 
Sampaio, P., Saraiva, P., \& Monteiro, A. (2012). A comparison and usage overview of business excellence models. The TQM Journal, 24(2), 181-200.

Silvestro, R. (2001). Towards a contingency theory of TQM in services-How implementation varies on the basis of volume and variety. International Journal of Quality \& Reliability Management, 18(3), 254-288.

Singh, S., \& Deshmukh, S. G. (1999). Quality initiatives in the service sector: a case. Total Quality Management, $10,5-16$.

Sousa, R., \& Voss, C. A. (2008). Contingency research in operations management practices. Journal of Operations Management, 26(6), 697-713.

Sousa, R., \& Voss, C.A. (2002). Quality management re-visited: a reflective review and agenda for future research. Journal of Operations Management, 20, 91-109.

Wayhan, V.B., \& Balderson, E.L. (2007). TQM and Financial Performance: What has Empirical Research Discovered? Total Quality Management \& Business Excellence, 18(4), 403-412.

Yasin, M., Czuchry, A., Dorsch, J., \& Small, M. (1999). In search of an optimal cost of quality: an integrated framework of operational efficiency and strategic effectiveness. Journal of Engineering and Technology Management, 16(2), 171-189.

Yeung, A.C.L., Chan, L.Y. \& Lee, T.S. (2003). An empirical taxonomy for quality management systems: a study of the Hong Kong electronics industry, Journal of Operations Management, 21, 45-62.

Yeung, A.C.L., Cheng, T.C.E., \& Lai, K., (2006). An operational and institutional perspective on total quality management. Production and Operations Management 15(1), 156-170. 
Figure 1. QM and organizational outcomes: nonlinear relationships ${ }^{1}$

a) Quadratic mode/s

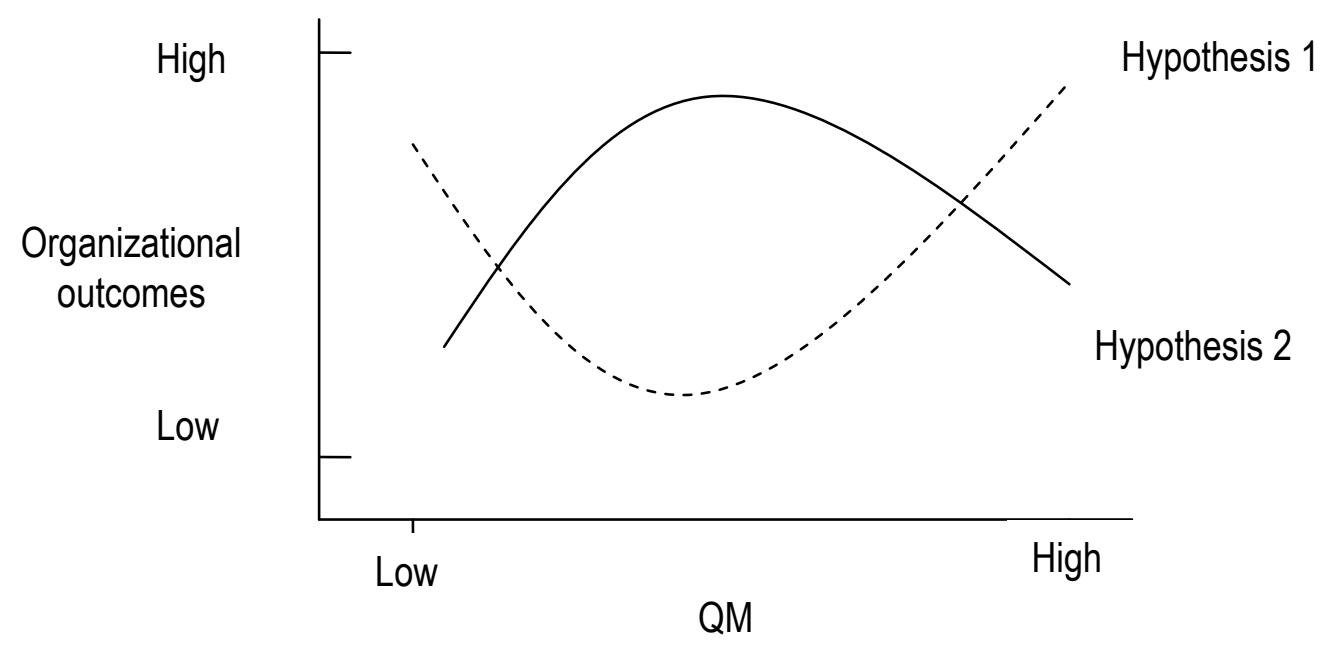

b) Cubic models

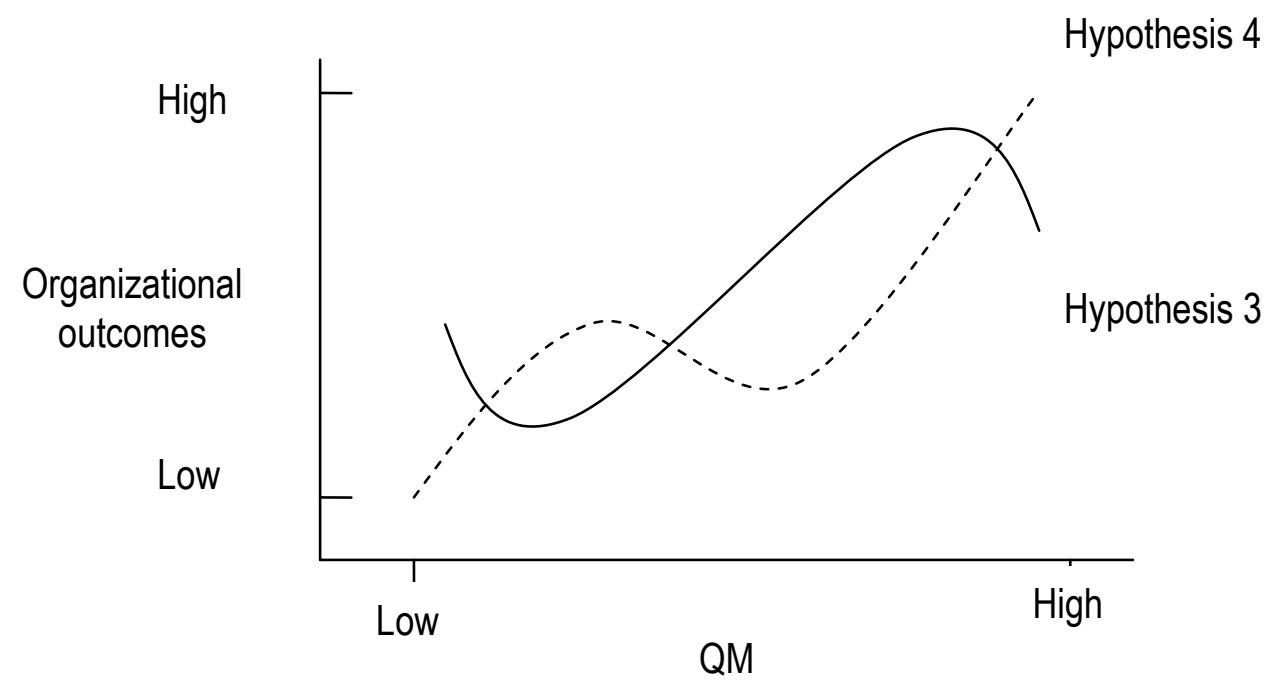

${ }^{1}$ Note: The functional forms represented are illustrative; examples of possible quadratic and cubic functional forms that would be framed within the proposed hypotheses. They aim to point to the presence of inflection points and the coexistence of positive and negative relationships. 
Figure 2. Relationship between QM and ROA

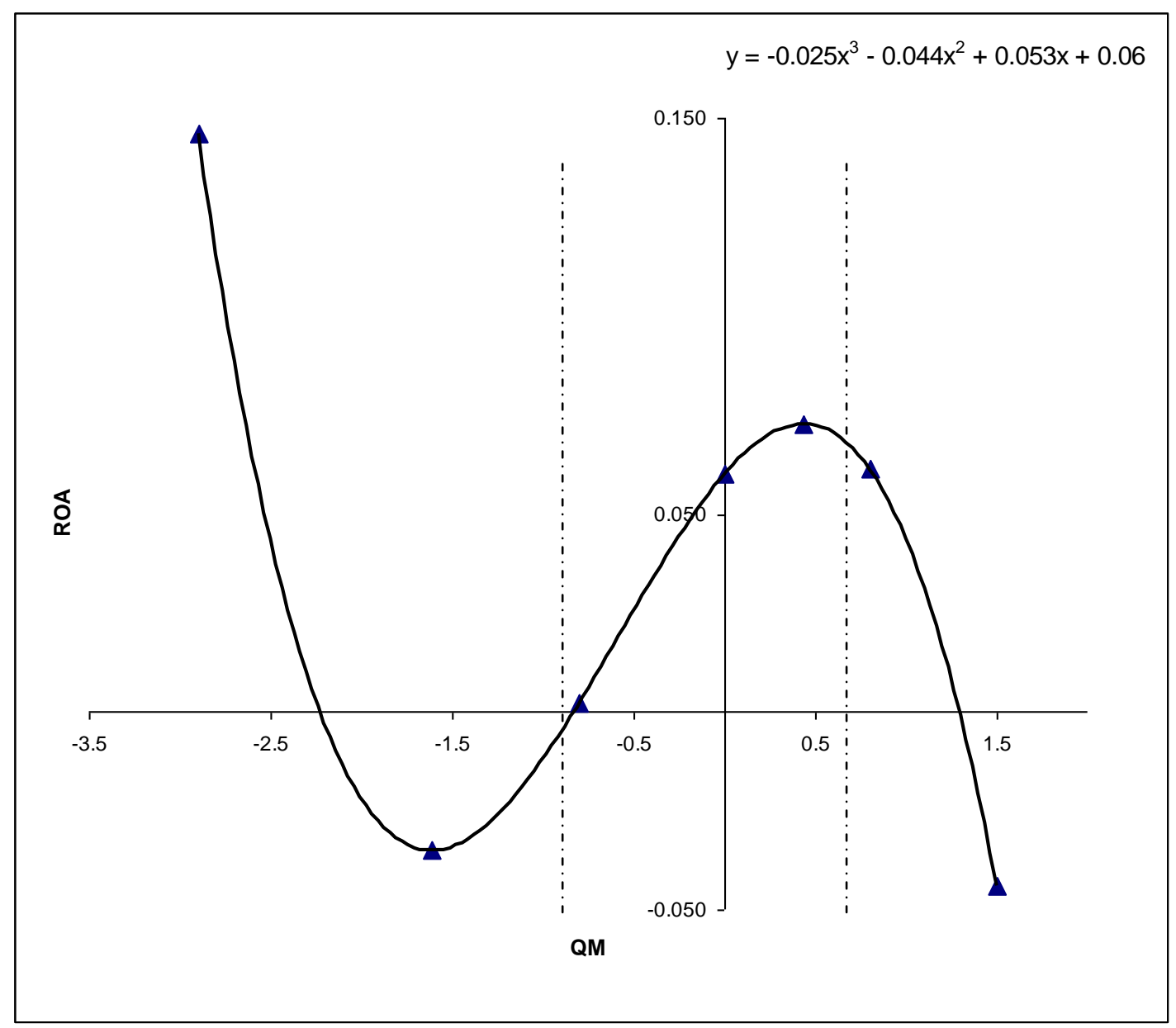


Table 1. Descriptive statistics and correlations $(N=168)$

\begin{tabular}{lccccccccc}
\hline \multicolumn{1}{c}{ Variables } & Mean & s.d. & 1 & 2 & 3 & 4 & 5 & 6 & 7 \\
\hline 1. Firm size (log) & 2.230 & 0.697 & 1 & & & & & \\
2. QM duration (years) & 7.473 & 7.543 & $0.365^{* * *}$ & 1 & & & & \\
3. Professional services & 0.184 & 0.389 & $0.247^{* * *}$ & $0.270^{* * *}$ & 1 & & & \\
4. Business services & 0.291 & 0.455 & $0.282^{* * *}$ & 0.055 & $-0.305^{* * *}$ & 1 & & \\
5. ROA 0405 & 0.065 & 0.100 & 0.055 & 0.069 & $0.154^{* *}$ & 0.101 & 1 & & \\
6. QM & 5.426 & 0.806 & $0.156^{* *}$ & $0.173^{* *}$ & 0.041 & 0.024 & 0.093 & 1 & \\
7. $\mathrm{ROA}_{0607}$ & 0.067 & 0.154 & 0.001 & 0.022 & 0.082 & 0.108 & $0.508^{* * *}$ & 0.111 & 1 \\
\hline & Note: & $* * * p<0.01 ; * *$ & $0.0 .05 * p<0.1$ (two-tailed) & & &
\end{tabular}

Table 2. Results of hierarchical regression analyses on ROA

\begin{tabular}{l|cccc}
\hline \multicolumn{1}{c|}{ Variables } & Model1 & Model2 & Model3 & Model4 \\
Firm size & -0.061 & -0.070 & -0.073 & -0.071 \\
QM duration & -0.009 & -0.020 & -0.021 & -0.026 \\
Professional services sector & 0.051 & 0.055 & 0.055 & 0.045 \\
Business services sector & 0.090 & 0.094 & 0.094 & 0.070 \\
ROA $_{0405}$ & $0.495^{* * *}$ & $0.489^{* * *}$ & $0.484^{* * *}$ & $0.518^{* * *}$ \\
QM & & 0.075 & 0.068 & $0.276^{* *}$ \\
$\mathrm{QM}^{2}$ & & & -0.015 & $-0.341^{* *}$ \\
$\mathrm{QM}^{3}$ & & & & $-0.504^{* * *}$ \\
$\mathrm{R}^{2}\left(\Delta \mathrm{R}^{2}\right)$ & 0.265 & $0.271(0.006)$ & $0.271(0.000)$ & $0.304(0.032)^{* * *}$ \\
Adjusted $\mathrm{R}^{2}$ & 0.243 & 0.244 & 0.239 & 0.268 \\
$F$ & $11.710^{* * *}$ & $9.969^{* * *}$ & $8.499^{* * *}$ & $8.662^{* * *}$ \\
\hline
\end{tabular}

Note: Standardized regression coefficients $* * * p<0.01 ; * * p<0.05 ; * p<0.10$ (two-tailed) 